\title{
Effect of stem cells combined with a polymer/ceramic membrane on osteoporotic bone repair
}

\author{
Adriana Luisa Goncalves ALMEIDA(a) \\ Gileade Pereira FREITAS(a) \\ Helena Bacha LOPES(a) \\ Rossano GIMENES(b) \\ Selma SIESSERE(c) (iD) \\ Luiz Gustavo SOUSA(c) \\ Marcio Mateus BELOTI(a) (D) \\ Adalberto Luiz ROSA(a) \\ (a) Universidade de São Paulo - USP, School \\ of Dentistry of Ribeirão Preto, Bone \\ Research Lab, Ribeirão Preto, SP, Brazil. \\ (b) Universidade Federal de Itajubá - Unifei, \\ Institute of Physics and Chemistry, Itajubá, \\ MG, Brazil \\ (c) Universidade de São Paulo - USP, School \\ of Dentistry of Ribeirão Preto, Department \\ of Basic and Oral Biology, Ribeirão Preto, \\ SP, Brazil.
}

Declaration of Interests: The authors certify that they have no commercial or associative interest that represents a conflict of interest in connection with the manuscript.

Corresponding Author:

Adalberto Luiz Rosa

E-mail: adalrosa@forp.usp.br

htps://doi.org/10.1590/1807-3107BOR-2019.vol33.0079

Submitted: February 22, 2019

Accepted for publication: June 6, 2019

Last revision: June 26, 2019
Abstract: Cell therapy associated with guided bone regeneration (GBR) can be used to treat bone defects under challenging conditions such as osteoporosis. This study aimed to evaluate the effect of mesenchymal stem cells (MSCs) in combination with a poly(vinylidenetrifluoroethylene)/barium titanate (PVDF-TrFE/BT) membrane on bone repair in osteoporotic rats. Osteoporosis was induced in female rats by bilateral removal of the ovaries (OVX) or sham surgery (SHAM), and the osteoporotic condition was characterized after 5 months by microtomographic and morphometric analyses. Calvarial defects were created in osteoporotic rats that immediately received the PVDFTrFE/BT membrane. After 2 weeks, bone marrow-derived MSCs from healthy rats, characterized by the expression of surface markers using flow cytometry, or phosphate-buffered saline (PBS) (Control) were injected into the defects and bone formation was evaluated 4 weeks post-injection by microtomographic, morphometric, and histological analyses. A reduction in the amount of bone tissue in the femurs of OVX compared with SHAM rats confirmed the osteoporotic condition of the experimental model. More bone formation was observed when the defects were injected with MSCs compared to that with PBS. The modification that we are proposing in this study for the classical GBR approach where cells are locally injected after a membrane implantation may be a promising therapeutic strategy to increase bone formation under osteoporotic condition.

Keywords: Bone and Bones; Cell- and Tissue-Based Therapy; Guided Tissue Regeneration; Mesenchymal Stem Cells; Osteoporosis.

\section{Introduction}

After experiencing damage due to trauma, surgical interventions, or pathologies, bone tissue can be repaired by a regeneration process that resembles the skeletal development. On the other hand, there are several situations where the exuberant healing capacity of bone tissue is surpassed by the extent of the damage or the concurrence of systemic conditions that disturb tissue metabolism. Among the systemic conditions, osteoporosis is the most prevalent bone pathology that has been reported to affect more than 200 million people around the world and has generated an estimated medical cost of 8 billion dollars in the United States in 2008.,2,3 
Osteoporosis occurs due to an imbalance in the process of bone remodeling that results in the degradation of bone microarchitecture and the reduction of tissue density, thereby increasing skeletal fragility and fracture risk. ${ }^{4}$ The occurrence of trauma or performing surgical procedures in the presence of osteoporosis represents a challenging condition that may require additional treatments such as bone grafts (autograft and allograft), biomaterials, and growth factors. ${ }^{5}$ However, these treatments could present some drawbacks, and there has been a growing interest for new treatment approaches such as bone tissue engineering and cell therapy.

The principle of guided bone regeneration (GBR) involves the use of membranes as barriers, and GBR has been extensively used in the fields of maxillofacial surgery and periodontology to improve bone healing. ${ }^{6,7}$ Recent research has demonstrated promising results using GBR in terms of bone repair of osteoporotic rat calvarial defects, wherein there was induction of more bone formation than that in untreated defects. ${ }^{8}$ Although there was increment in bone repair induced by the composite poly(vinylidene-trifluoroethylene)/ barium titanate (PVDF-TrFE/BT) membrane under osteoporotic condition, only small amount of bone formation was observed. This could be, at least in part, due to a decreased migration of mesenchymal stem cells (MSCs) to the defects induced by osteoporosis as it is well known that MSC migration and invasion of injured areas are critical to the process of bone healing. ${ }^{9,10}$ In this context, in our earlier study, we had combined GBR with cell therapy using an approach where the composite PVDF-TrFE/BT membrane was implanted into the bone defects and 2 weeks postimplantation cells were injected into the membrane. ${ }^{11}$ Considering that this approach was beneficial to bone repair in the calvarial defects of normal rats compared with GBR alone, ${ }^{11}$ we hypothesized that the combination of cell therapy and GBR induces more bone formation than GBR alone under osteoporotic condition. To test our hypothesis, osteoporosis was induced in female rats by bilateral ovariectomy, and then calvarial defects were created and immediately implanted with PVDF-TrFE/BT membranes. After 2 weeks, MSCs were injected into the defects and bone formation was evaluated 4 weeks post-injection by microtomographic, morphometric, and histological analyses.

\section{Methodology}

\section{Osteoporosis induction}

The experimental procedures using animals were carried out under the guidelines of the Committee of Ethics in Animal Research (Protocol \# 2014.1.795.58.0). Osteoporosis was induced by bilateral ovariectomy. ${ }^{12}$ Fourteen female Wistar rats weighing 150 g were anesthetized by injecting a combination of ketamine (7 mg/100 g body weight; Agener União, São Paulo, Brazil) and xylazine $(0.6 \mathrm{mg} / 100 \mathrm{~g}$ body weight; Calier, MG, Brazil) to be ovariectomized (OVX). A bilateral abdominal incision was performed to expose and remove the ovaries, and the skin was sutured with nylon 4.0 (Ethicon, São Paulo, Brazil). Then, single doses of antibiotics and analgesics were administered. Another set of four female Wistar rats were submitted to the same surgical procedure, with the exception of the excision of ovaries, to reproduce the effects of the surgical stress (SHAM). After 5 months, osteoporosis was characterized and the OVX animals were used for all the subsequent experiments.

\section{Characterization of osteoporotic condition}

The distal epiphysis of the femurs and the calvarial fragments (removed to create bone defects) of OVX and SHAM rats were used to characterize osteoporosis by microtomographic and morphometric analyses. The animals $(n=4$ in each group, OVX and SHAM) were euthanized, and the femurs were removed and stored in $10 \%$ formalin buffered with $0.1 \mathrm{M}$ sodium cacodylate, $\mathrm{pH} 7.0$ (Merck, HE, Germany). The calvarial fragments $(n=5$ in each group, OVX and SHAM) were obtained during the creation of the bone defects as described below and stored in the same solution used for the femurs. Morphometric analysis was carried out using high-resolution SkyScan 1172 microtomograph (Bruker, Kontich, Belgium). The images were obtained at 9.8 pixel size, $60 \mathrm{kVp}$, and $165 \mathrm{~mA}$, and the NRecon software (version 1.6.10.4, Bruker) was used for the reconstructions with the following parameters: smoothing set at 2, ring artifact correction set at 6 , and beam hardening correction 
set at $20 \%$. The reconstructions were analyzed by the CTAn software (version 1.15.4.0, Bruker) to evaluate bone mineral density. ${ }^{13,14}$

\section{Isolation and culture of MSCs}

Bone marrow cells were flushed from the femurs of healthy male Wistar rats $(n=3$, weighing $250-300$ g), pooled, and cultured in alpha minimum essential medium (Gibco-Invitrogen, Grand Island, NY, USA) supplemented with $10 \%$ fetal bovine serum (GibcoInvitrogen), $50 \mu \mathrm{g} / \mathrm{ml}$ gentamicin (Gibco-Invitrogen), and $0.3 \mu \mathrm{g} / \mathrm{ml}$ fungizone (Gibco-Invitrogen). After 48 $\mathrm{h}$, the medium was refreshed allowing the selection of MSCs by adherence to the tissue plastic culture and expansion until subconfluence. Then, the MSCs were enzymatically released and injected into the calvarial defects as described below. The cells were kept at $37^{\circ} \mathrm{C}$ and humidified atmosphere containing $5 \% \mathrm{CO}_{2}$ and $95 \%$ air, and the medium was changed every $72 \mathrm{~h}$.

\section{Characterization of MSCs}

Subconfluent MSCs $\left(2 \times 10^{5}\right.$ cells per tube) were incubated separately with monoclonal anti-rat antibodies against CD29, CD31, CD90, CD106 (BD Biosciences, Franklin Lakes, NJ, USA), and CD34 (Santa Cruz Biotechnology, Santa Cruz, CA, USA) for $30 \mathrm{~min}$ at room temperature. Then, the cells were homogenized using $2 \mathrm{ml}$ phosphate-buffered saline (PBS, Gibco-Invitrogen)/Tween-20 (Sigma-Aldrich) and centrifuged at $360 \mathrm{~g}$ for $5 \mathrm{~min}$. The cell pellet was washed with PBS (Gibco-Invitrogen), and $500 \mu 1$ of formaldehyde (Merck, Germany) diluted in PBS (Gibco-Invitrogen) were added. Flow cytometry was performed in a FACSCanto ${ }^{\mathrm{TM}}$ system (BD Biosciences), and data were presented as percentage of cells expressing each surface marker.

\section{In vivo bone formation}

Ten OVX rats were anesthetized as described above. A skin incision was performed to expose the parietal bone, and a unilateral 5-mm diameter calvarial defect was created and immediately implanted with the PVDF-TrFE/BT membrane positioned between dura mater and inner calvaria cortical bone. The PVDFTrFE/BT membrane was used as it can promote bone formation in both normal and osteoporotic rats. ${ }^{8,11}$ The defect size was selected based on previous studies where no significant bone formation was observed even 12 weeks post-surgery. ${ }^{15,16}$ Two weeks postimplantation, the animals were randomly distributed to receive local injections of $50 \mu \mathrm{l}$ of PBS (GibcoInvitrogen) containing $5 \times 10^{6} \mathrm{MSC}$ collected from healthy rats $(n=5)$ or $50 \mu 1$ of PBS without MSCs (Control, $\mathrm{n}=5$ ). The number of cells was selected on the basis of a previous study that used different cell concentrations (data not shown) and on data published in the literature. ${ }^{17}$ These procedures were performed with caution to deliver the injection content into the bone defects on the top of the PVDF-TrFE/BT membrane. Four weeks post-injection, the rats were euthanized, and the calvariae were harvested and processed for morphometric and histological analyses.

Considering the 5-mm diameter defect and the average thickness of the calvaria, the selected region of interest (ROI) was 5-mm diameter $\times 0.6$-mm thickness. The segmentation of bone was defined in the range of $60-110$ in a histogram gray scale from 0 to 255 to isolate bone tissue from the membrane. To quantify only the bone formation induced by the injection containing either MSCs or PBS, the morphometric analysis was carried out only into the defect, on the top of the PVDF-TrFE/BT membrane, delimited by the selected ROI, and according to the American Society for Bone and Mineral Research. The following parameters were generated: bone volume, bone volume/total volume, bone surface, bone mineral density, trabecular thickness, trabecular number, and trabecular separation. ${ }^{13,14}$ After conducting the microtomographic and morphometric analyses, the samples were processed to obtain undecalcified tissue sections as described elsewhere. ${ }^{11}$ The histological description of the tissues grown on top of the PVDFTrFE/BT membrane was made from images obtained using a light microscope (Leica Microsystems Wetzlar $\mathrm{GmbH}$, Germany) equipped with a digital camera (DFC 310 FX camera, Leica Microsystems).

\section{Statistical analysis}

All data were expressed as mean \pm standard deviation. The data of osteoporosis characterization (power: 0.99) and bone formation (power: 0.81) were 
compared using the Student's $t$-test, and the level of significance was set at $p \leq 0.05$. Power calculations were performed using the statistical power analysis software from the Universität Düsseldorf (http:// www.gpower.hhu.de) considering the sample sizes used in this study.

\section{Results}

\section{Characterization of osteoporotic condition}

Three-dimensional reconstructed microtomographic images revealed that OVX (Figure 1A) and SHAM (Figure 1B) femurs displayed different bone structure. The OVX femurs (Figure 1A) exhibited larger dimensions and altered external contour with reduction of trabecular density compared with SHAM (Figure 1B), in addition to a lower bone mineral density $(p=0.001)$ than that of SHAM (Figure 1C). Regarding calvarial fragments, a similar bone morphology was observed by comparing OVX (Figure 1D) and SHAM (Figure 1E) with calvaria from OVX, which exhibited a lower bone mineral density than SHAM (Figure 1F).

\section{Characterization of MSCs}

The fluorescence background of nonlabeled cells was 3.5\% (Figure 2A), which was subtracted from each percentage of the labeled cells. The MSCs harvested from healthy rats exhibited a low expression of CD31 (Figure 2B) and CD34 (Figure 2C), both of which are hematopoietic markers, an intermediate expression of CD106 (Figure 2D), and a high expression of CD29 (Figure 2E) and CD90 (Figure 2F); the latter three are markers of MSCs. Taken together, these data indicate that the majority of this cell population is composed of MSCs.

\section{In vivo bone formation}

Three-dimensional reconstructed microtomographic images demonstrated the formation of bone tissue in all the defects irrespective of the treatment (Figure 3A and B). However, it was evident that injection of MSCs induced higher bone formation (Figure 3A) than that with PBS injection (Figure 3B). Moreover, MSCs induced bone formation in the middle of the defects (Figure 3A), whereas PBS induced bone formation primarily in the periphery (Figure 3B). Confirming these observations, the morphometric analysis revealed that bone volume (Figure $3 \mathrm{C}, \mathrm{p}=0.05$ ), bone volume/total volume (Figure 3D, $p=0.02$ ), bone mineral density (Figure 3F, $\mathrm{p}=0.001$ ), and trabecular number (Figure $3 \mathrm{H}, \mathrm{p}=0.03$ ) were higher in defects treated with MSCs than in defects treated with PBS. Bone surface (Figure 3E, $p=0.07$ ), trabecular thickness (Figure 3G, $p=0.55$ ), and trabecular separation (Figure $3 \mathrm{I}, \mathrm{p}=0.89$ ) were not statistically different between MSC and PBS treatments.

Results of the histological sections confirmed the morphometric results. On the top of the PVDFTrFE/BT membrane, more bone tissue was observed almost bridging the defects treated with MSCs compared with those treated with PBS (Figure 4A and $\mathrm{B})$. A common thin layer of connective tissue between the PVDF-TrFE/BT membrane and the newly formed bone without inflammatory signs was observed in both treatments (Figure 4C and D).

\section{Discussion}

This study aimed to evaluate bone formation in osteoporotic rats induced by the combination of cell therapy and GBR. Osteoporosis was induced in female rats by bilateral ovariectomy (OVX), and then calvarial defects were created and immediately implanted with PVDF-TrFE/BT membrane. After 2 weeks, either MSCs or PBS (Control) was injected into the defects on the top of the membrane, and bone formation was evaluated 4 weeks postinjection by microtomographic, morphometric, and histological analyses. Bone formation was observed irrespective of the treatment, but a significantly higher amount of bone tissue was detected in the defects treated with the combination of MSCs and the membrane.

The experimental model selected was that of OVX rats, in which estrogen deficiency induces osteoporosis, with the consequent loss of bone mass and its sequelae, similar to that found in postmenopausal women. ${ }^{18,19}$ The induction of osteoporosis by OVX in rats is one of the most suitable models as it affects several bones. ${ }^{20}$ In the present study, the analyses were limited to the trabecular 

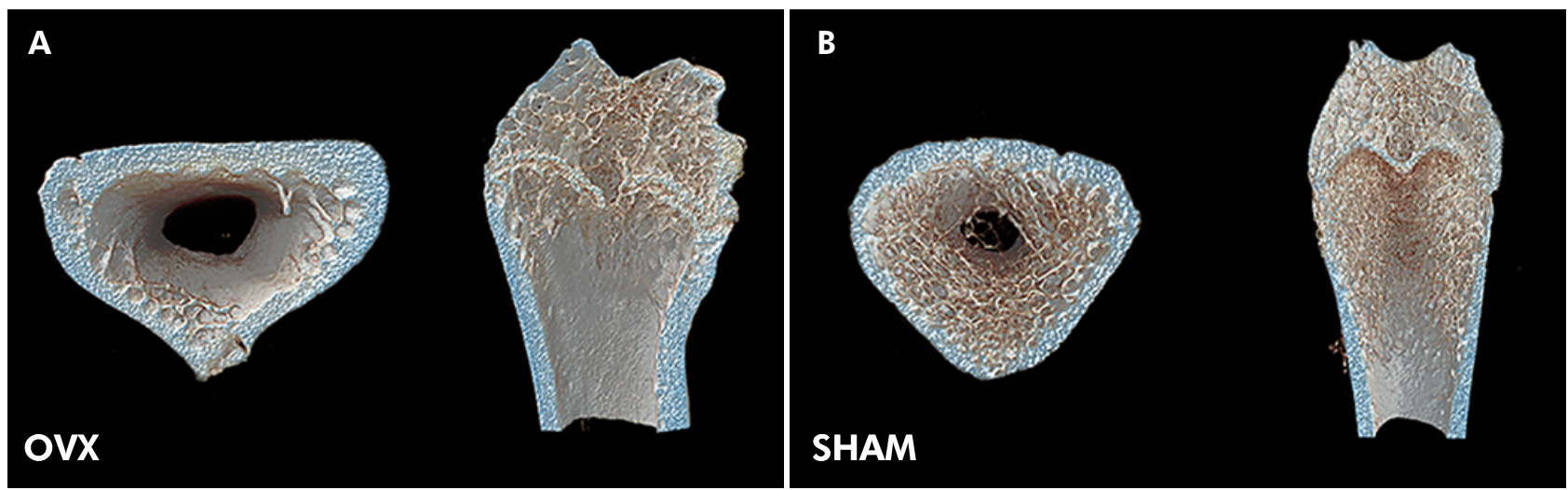

C

Bone Mineral Density
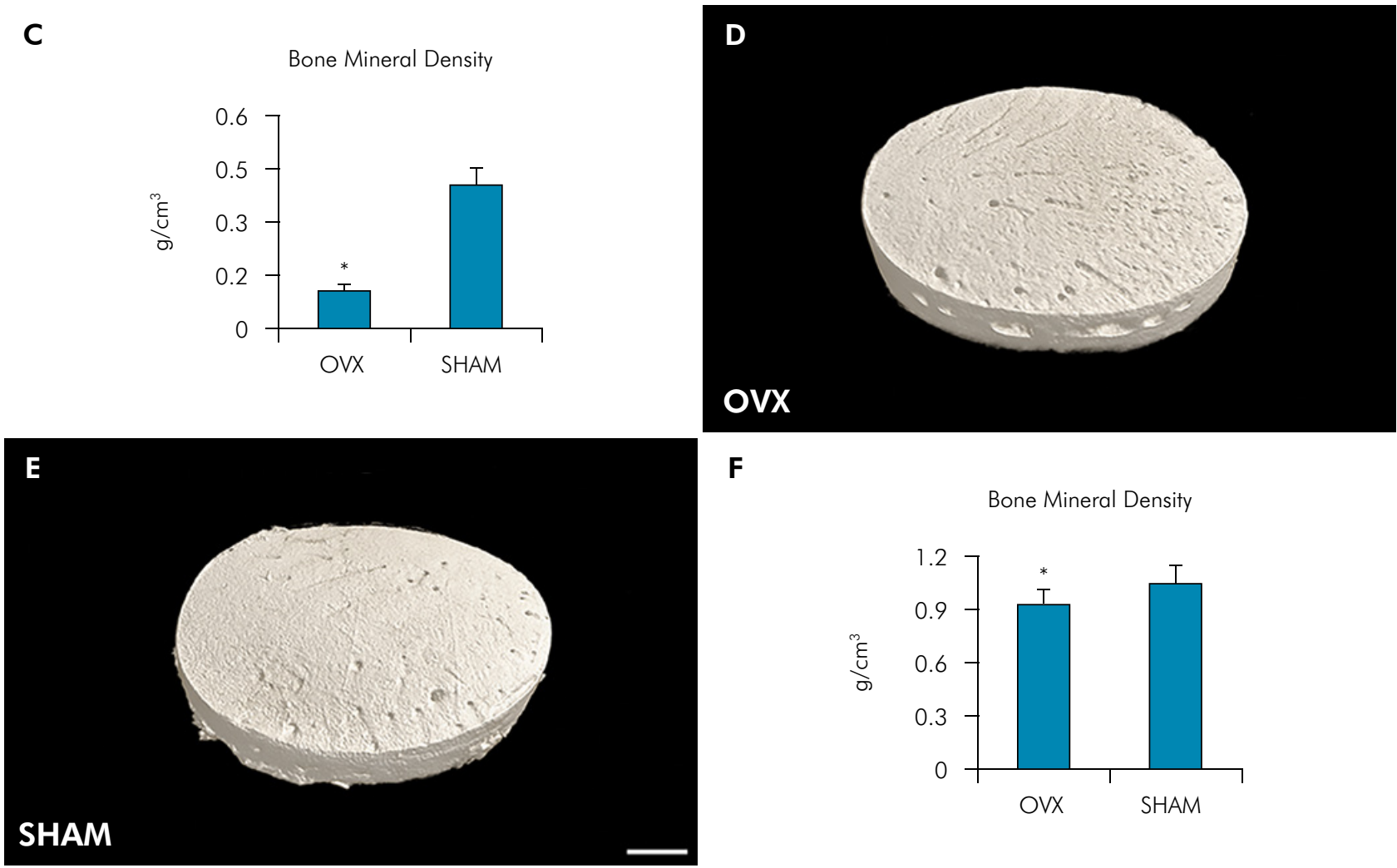

$\mathbf{F}$ Bone Mineral Density

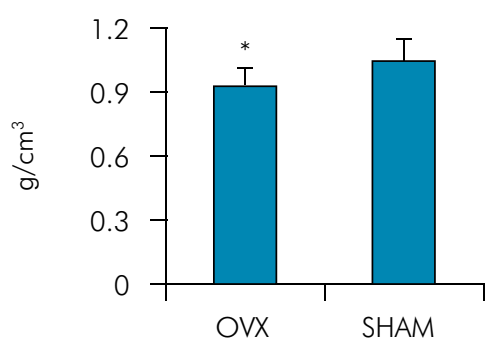

Figure 1. Three-dimensional reconstructed microtomographic images and bone mineral density of femurs and calvarial fragments from osteoporotic (OVX) and normal (SHAM) rats, 5 months post-ovariectomy or sham surgery. The OVX femurs (A) exhibited a reduced trabecular density compared with SHAM (B), in addition to a reduced bone mineral density (C). The calvarial fragments showed a similar bone morphology by comparing OVX (D) and SHAM (E) with OVX displaying a lower bone mineral density than $\operatorname{SHAM}(F)$. Data $(C, n=4$, and $F, n=5)$ are presented as mean \pm standard deviation. Asterisks indicate statistically significant difference $(p \leq 0.05)$. Scale bar: $A-B=2 \mathrm{~mm}$ and $D-E=8 \mathrm{~mm}$.

bone microarchitecture of the distal epiphysis of the femurs as it is a region that is particularly sensitive to the effects of OVX and recognized as a key component of quality and bone strength (resistance), comparable to osteoporosis in humans and detectable by microtomography. ${ }^{18,21,22,23,24}$ The results revealed low bone quality of the femurs of
OVX rats compared with SHAM rats. However, the lack of a statistically significant difference between the groups in terms of trabecular thickness may be associated with trabecular thickening in osteoporotic rats as an attempt to compensate for the decrease in bone resistance produced by trabecular resorption..$^{25}$ Results of the microtomographic and morphometric 
A

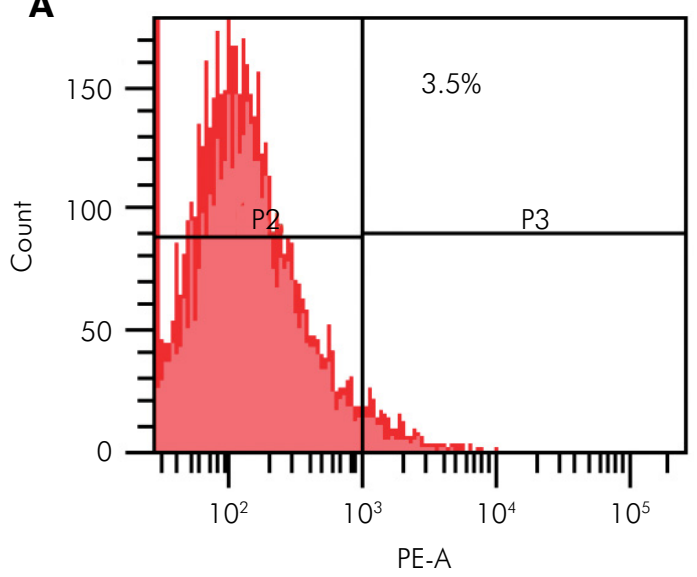

C

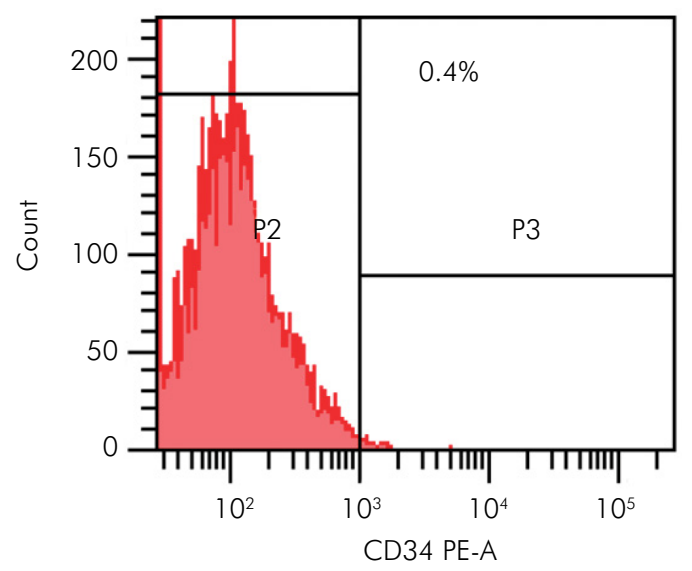

E

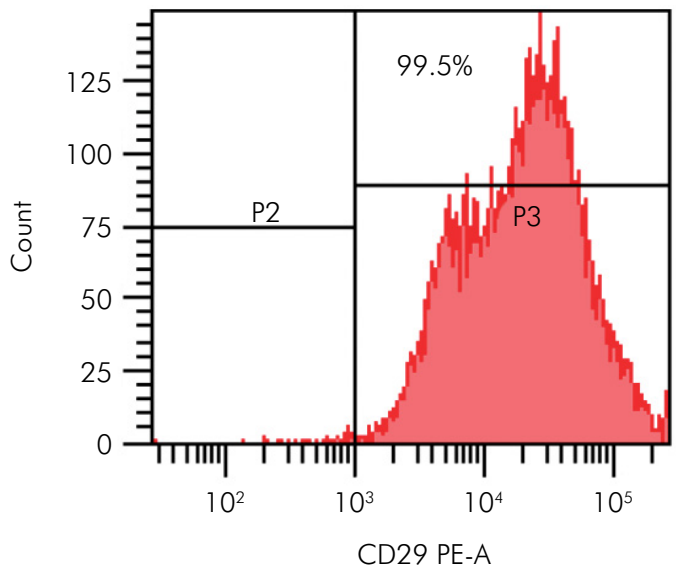

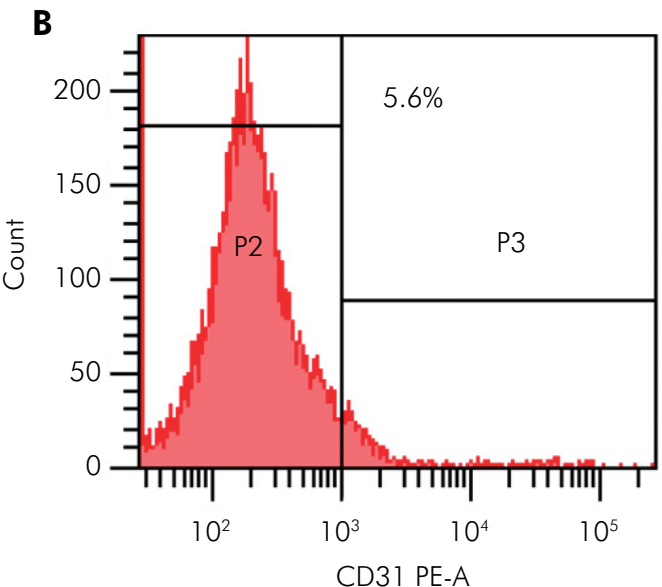

D

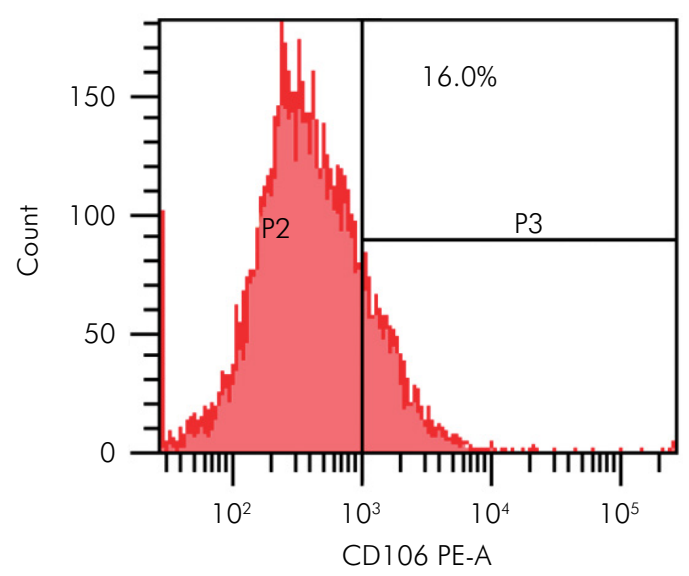

$\mathbf{F}$

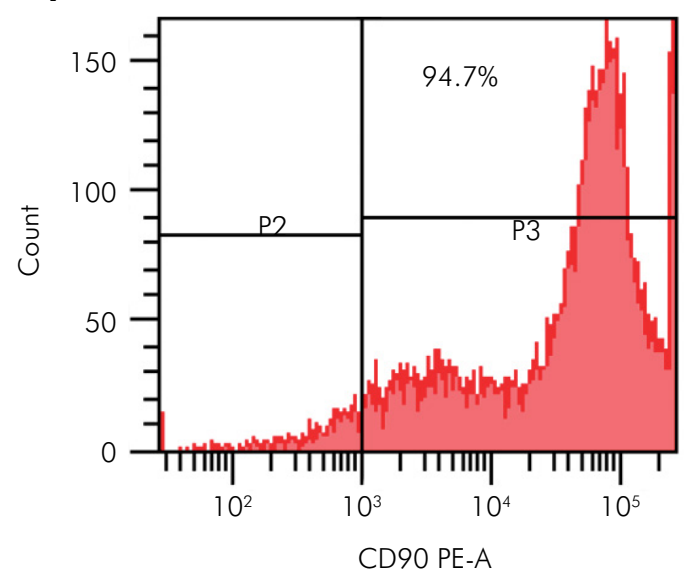

Figure 2. Identification of surface markers of MSCs by flow cytometry. The fluorescence background of nonlabeled cells (A) was subtracted from each percentage of labeled cells. Percentage of expression of CD31 (B), CD34 (C), CD106 (D), CD29 (E), and CD90 (F).

analyses confirmed the osteoporotic pattern of the selected experimental model and substantiate the results described in the literature. ${ }^{20,26,27,28}$
One of the critical factors to the success of GBR technique is the choice of a suitable membrane ${ }^{7}$. In this study, we selected the PVDF-TrFE/BT membrane 

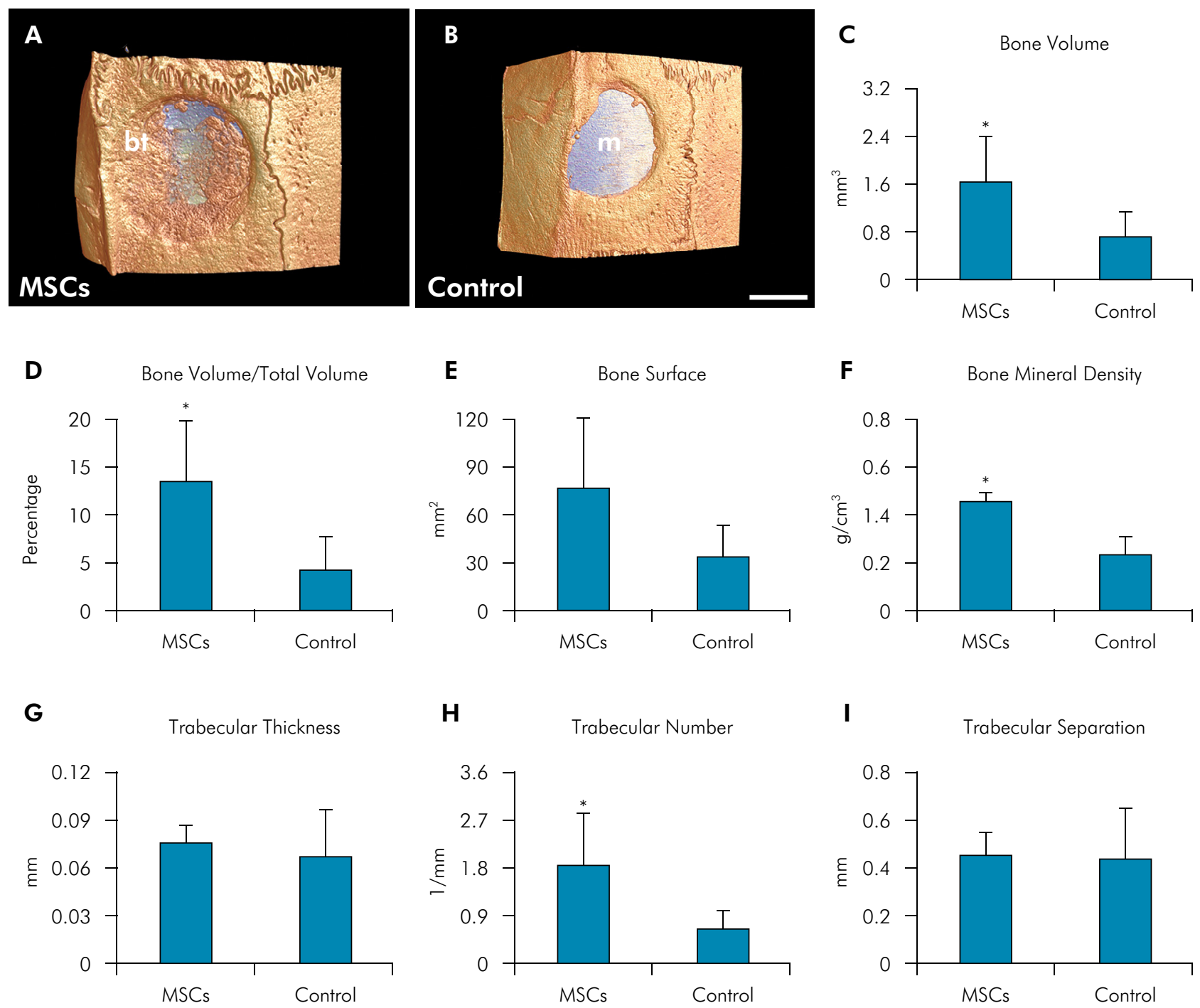

I

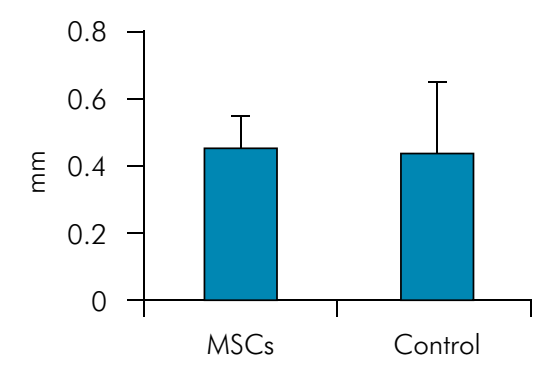

Figure 3. Three-dimensional reconstructed microtomographic images and morphometric parameters of bone formation in osteoporotic rat calvarial defects implanted with PVDF-TrFE/BT membrane and injected with MSCs or PBS (Control), 4 weeks postinjection. Defects injected with MSCs (A) exhibited greater bone formation than defects injected with PBS (B). Bone volume (C), bone volume/total volume (D), bone mineral density $(\mathrm{F})$, and trabecular number $(\mathrm{H})$ were higher in defects treated with MSCs than in defects treated with PBS. Data $(\mathrm{C}-1)$ are presented as mean \pm standard deviation $(\mathrm{n}=5)$. Asterisks indicate statistically significant difference $(p \leq 0.05)$. Scale bar: $A-B=2 \mathrm{~mm}$. bt: bone tissue; $m$ : PVDF-TrFE/BT membrane.

due to its good in vitro biocompatibility and the capacity to induce bone formation in both normal and osteoporotic rats and decrease bone resorption by inhibiting osteoclastogenesis. ${ }^{8,29,30,31,32,33}$ In addition, in a previous study, the PVDF-TrFE/BT membrane was successfully combined with osteoblast injections to increase the amount of bone formation in the calvarial defects of normal rats. ${ }^{11}$

For bone regeneration based on the use of cells, several tissues have been investigated as cell source; however, the bone marrow still remains the most common source, at least in part, due to its ease of accessibility and multilineage differentiation potential. ${ }^{34}$ In fact, we had previously demonstrated the ability of these cells to differentiate into multilineages, ${ }^{35}$ which was associated with the expression of cell surface markers described in the present study, thus allowing to qualify them as MSCs. In this study, we opted for using these bone marrowderived MSCs harvested from healthy animals 


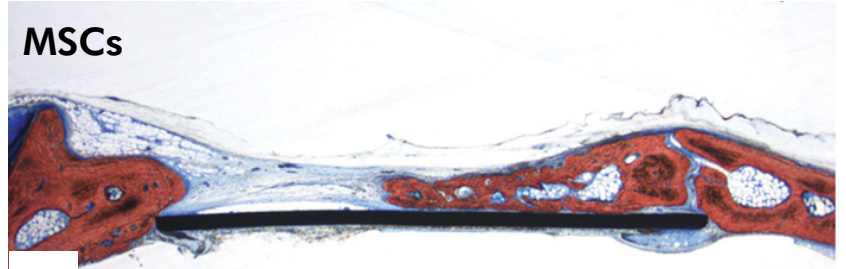

A
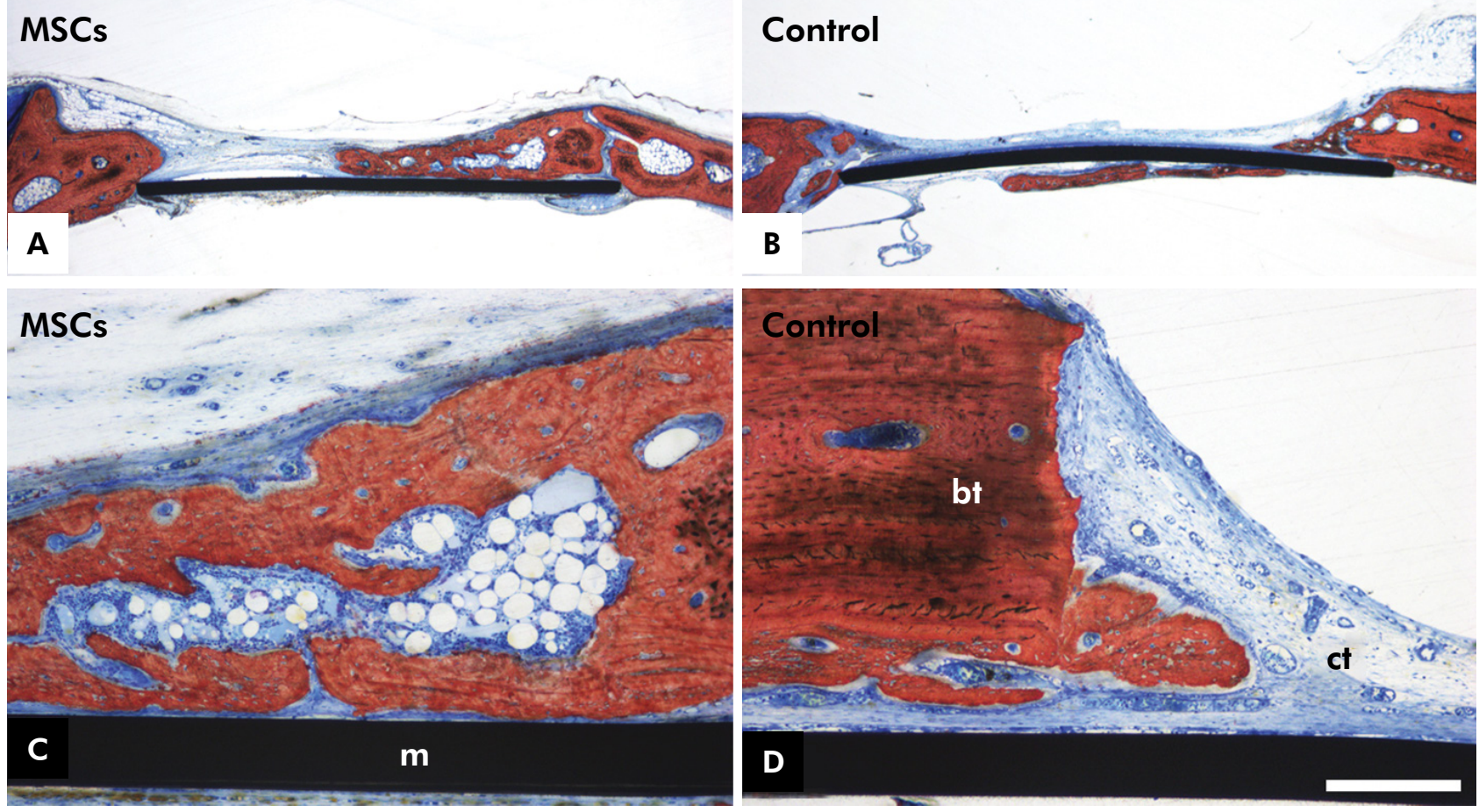

Figure 4. Light microscopy of rat calvarial bone defects implanted with PVDF-TrFE/BT membrane and injected with MSCs or PBS (Control), 4 weeks post-injection. Defects injected with MSCs (A and C) exhibited greater bone formation than defects injected with PBS ( $B$ and D), and a significant area of the defects injected with PBS ( $B$ and D) was filled with connective tissue. Alizarin red and Stevenel's blue stain. bt: bone tissue; ct: connective tissue; m: PVDF-TrFE/BT membrane. Scale bar: A-B = 800 $\mu \mathrm{m} ; \mathrm{C}-\mathrm{D}=200 \mu \mathrm{m}$.

based on previous reports where these cells either undifferentiated or differentiated into osteoblasts displayed similar potential to induce bone formation, combined with the fact that bone marrow-derived cells induced more bone formation than adiposederived cells. ${ }^{11,36}$ Furthermore, the cell injection was performed 2 weeks post-surgery to prevent the contact of MSCs with the initial inflammatory microenvironment of the bone defect, which could induce apoptosis. ${ }^{37}$ It is worth noting that the use of the same approach, membrane implantation 2 weeks before cell injection, revealed that the cells remained in the bone defect for up to 25 days. ${ }^{11}$

As mentioned earlier, the strategy of combining GBR with cell therapy has been used to increase bone formation in rat calvarial defects. ${ }^{11,38,39}$ The combination of MSCs with either synthetic $\beta$-tricalciumphosphate or collagen membrane enhanced bone formation compared with the use of biomaterials implanted without cells in rat calvarial defects. ${ }^{38,39}$ In this study, we present evidence that this approach is also effective in the presence of osteoporosis. In fact, some of the morphometric parameters and the microtomographic and histological images revealed higher amount of bone formation in those defects injected with MSCs than in the defects treated with PBS after the implantation of the PVDF-TrFE/BT membrane. Since the morphometric analysis was carried out only into the bone tissue found in the defect, on the top of the membrane, the results confirmed that the cells were effective in increasing bone formation. In addition, the evaluation of bone mineral density revealed that MSCs yield more mineralized bone tissue. Comparison of the morphometric parameters of defects treated with PVDF-TrFE/BT membranes without cells in osteoporotic rats described in this study and in normal rats described elsewhere ${ }^{11}$ revealed more bone formation in normal rats, thus confirming that osteoporosis impairs the process of bone repair. ${ }^{40}$ Interestingly, the pattern of bone formation was different between the treatments, wherein it was 
spread out in the MSC-injected defects, whereas in the PBS-injected defects, the bone formation was limited to the periphery. In common, both treatments resulted in an intervening connective tissue between bone tissue and the PVDF-TrFE/BT membrane, which appears to be a characteristic of this membrane. ${ }^{30}$

\section{Conclusion}

We have demonstrated that the proposed modification of the classical GBR approach, which involves local injection of cells after the implantation of a membrane, is effective in increasing bone formation in the presence of osteoporosis. It is worth noting that none of the defects treated with GBR and cell injection exhibited complete bone repair. As MSCs were used after harvesting and expansion, future studies should consider the use of the combination of cells with growth factors or the use of genetically modified cells in an attempt to improve the osteogenic potential of these cell populations to induce complete bone regeneration.

\section{Acknowledgments}

Roger Rodrigo Fernandes and Sebastião Carlos Bianco are acknowledged for technical assistance during the experiments. CNPq (456871/2013-6), FAPEMIG (TEC-APQ-03013-15) and FAPESP (2015/21439-6) for financial support.

\section{References}

1. Blume SW, Curtis JR. Medical costs of osteoporosis in the elderly Medicare population. Osteoporos Int. 22011 Jun;22(6):1835-44. https://doi.org/10.1007/s00198-010-1419-7

2. Reginster JY, Burlet N. Osteoporosis: a still increasing prevalence. Bone. 2006 Feb;38(2 Suppl 1):S4-9. https://doi.org/10.1016/i.bone.2005.11.024

3. Cooper C. Epidemiology of osteoporosis. Osteoporos Int. 1999;9(S2 Suppl 2):S2-8. https://doi.org/10.1007/PL00004156

4. Consensus development conference. Consensus development conference: prophylaxis and treatment of osteoporosis. Am J Med. 1991 Jan;90(1):107-10. https://doi.org/10.1016/0002-9343(91)90512-V

5. Pesce V, Speciale D, Sammarco G, Patella S, Spinarelli A, Patella V. Surgical approach to bone healing in osteoporosis. Clin Cases Miner Bone Metab. 2009 May;6(2):131-5.

6. Li H, Zheng J, Zhang S, Yang C, Kwon YD, Kim YJ. Experiment of GBR for repair of peri-implant alveolar defects in beagle dogs. Sci Rep. 2018 Nov;8(1):16532. https://doi.org/10.1038/s41598-018-34805-w

7. Dimitriou R, Mataliotakis GI, Calori GM, Giannoudis PV. The role of barrier membranes for guided bone regeneration and restoration of large bone defects: current experimental and clinical evidence. BMC Med. 2012 Jul;10(1):81. https://doi.org/10.1186/1741-7015-10-81

8. Scalize PH, Bombonato-Prado KF, de Sousa LG, Rosa AL, Beloti MM, Semprini M, et al. Poly(Vinylidene Fluoride-Trifluorethylene)/barium titanate membrane promotes de novo bone formation and may modulate gene expression in osteoporotic rat model. J Mater Sci Mater Med. 2016 Dec;27(12):180. https://doi.org/10.1007/s10856-016-5799-x

9. Sanghani-Kerai A, Coathup M, Samazideh S, Kalia P, Silvio LD, Idowu B, et al. Osteoporosis and ageing affects the migration of stem cells and this is ameliorated by transfection with CXCR4. Bone Joint Res. 2017 Jun;6(6):358-65. https://doi.org/10.1302/2046-3758.66.BJR-2016-0259.R1

10. Tarantino U, Cerocchi I, Scialdoni A, Saturnino L, Feola M, Celi M, et al. Bone healing and osteoporosis. Aging Clin Exp Res. 2011 Apr;23(2 Suppl):62-4.

11. Freitas GP, Lopes HB, Almeida AL, Abuna RP, Gimenes R, Souza LE, et al. Potential of osteoblastic cells derived from bone marrow and adipose tissue associated with a polymer/ceramic composite to repair bone tissue. Calcif Tissue Int. 2017 Sep;101(3):312-20. https://doi.org/10.1007/s00223-017-0282-3

12. Kalu DN, Hardin RR, Cockerham R. Evaluation of the pathogenesis of skeletal changes in ovariectomized rats. Endocrinology. 1984 Aug;115(2):507-12. https://doi.org/10.1210/endo-115-2-507

13. Dempster DW, Compston JE, Drezner MK, Glorieux FH, Kanis JA, Malluche H, et al. Standardized nomenclature, symbols, and units for bone histomorphometry: a 2012 update of the report of the ASBMR Histomorphometry Nomenclature Committee. J Bone Miner Res. 2013 Jan;28(1):2-17. https://doi.org/10.1002/jbmr.1805 
Effect of stem cells combined with a polymer/ceramic membrane on osteoporotic bone repair

14. Parfitt AM, Drezner MK, Glorieux FH, Kanis JA, Malluche H, Meunier PJ, et al. Bone histomorphometry: standardization of nomenclature, symbols, and units. Report of the ASBMR Histomorphometry Nomenclature Committee. J Bone Miner Res. 1987 Dec;2(6):595-610. https://doi.org/10.1002/ibmr.5650020617

15. Sicchieri LG, Crippa GE, de Oliveira PT, Beloti MM, Rosa AL. Pore size regulates cell and tissue interactions with PLGA-CaP scaffolds used for bone engineering. J Tissue Eng Regen Med. 2012 Feb;6(2):155-62. https://doi.org/10.1002/term.422

16. Bosch C, Melsen B, Vargervik K. Importance of the critical-size bone defect in testing bone-regenerating materials. J Craniofac Surg. 1998 Jul;9(4):310-6. https://doi.org/10.1097/00001665-199807000-00004

17. Liao Y, Zhang XL, Li L, Shen FM, Zhong MK. Stem cell therapy for bone repair: a systematic review and meta-analysis of preclinical studies with large animal models. Br J Clin Pharmacol. 2014 Oct;78(4):718-26. https://doi.org/10.1111/bcp.12382

18. Thompson DD, Simmons HA, Pirie CM, Ke HZ. FDA Guidelines and animal models for osteoporosis. Bone. 1995 Oct;17(4 Suppl):125S-33S. https://doi.org/10.1016/8756-3282(95)00285-L

19. Kalu DN. The ovariectomized rat model of postmenopausal bone loss. Bone Miner. 1991 Dec;15(3):175-91. https://doi.org/10.1016/0169-6009(91)90124-I

20. Lelovas PP, Xanthos TT, Thoma SE, Lyritis GP, Dontas IA. The laboratory rat as an animal model for osteoporosis research. Comp Med. 2008 Oct;58(5):424-30.

21. Francisco JI, Yu Y, Oliver RA, Walsh WR. Relationship between age, skeletal site, and time post-ovariectomy on bone mineral and trabecular microarchitecture in rats. J Orthop Res. 2011 Feb;29(2):189-96. https://doi.org/10.1002/jor.21217

22. Müller R. The Zürich experience: one decade of three-dimensional high-resolution computed tomography. Top Magn Reson Imaging. 2002 Oct;13(5):307-22. https://doi.org/10.1097/00002142-200210000-00003

23. Turner AS. Animal models of osteoporosis—necessity and limitations. Eur Cell Mater. 2001 Jun;1:66-81. https://doi.org/10.22203/eCM.v001a08

24. Dempster DW. The contribution of trabecular architecture to cancellous bone quality. J Bone Miner Res. 2000 Jan;15(1):20-3. https://doi.org/10.1359/jbmr.2000.15.1.20

25. Marcu F, Bogdan F, Muțiu G, Lazăr L. The histopathological study of osteoporosis. Rom J Morphol Embryol. 2011;52(1 Suppl):321-5.

26. Scalize PH, de Sousa LG, Regalo SC, Semprini M, Pitol DL, da Silva GA, et al. Low-level laser therapy improves bone formation: stereology findings for osteoporosis in rat model. Lasers Med Sci. 2015 Jul;30(5):1599-607. https://doi.org/10.1007/s10103-015-1773-y

27. Kosugi K, Yonezu H, Kawashima S, Honda K, Arai Y, Shibahara T. A longitudinal study of the effect of experimental osteoporosis on bone trabecular structure in the rat mandibular condyle. Cranio. 2013 Apr;31(2):140-50. https://doi.org/10.1179/crn.2013.022

28. Siéssere S, de Sousa LG, Issa JP, lyomasa MM, Pitol DL, Barbosa AP, et al. Application of low-level laser irradiation (LLLI) and rhBMP-2 in critical bone defect of ovariectomized rats: histomorphometric evaluation. Photomed Laser Surg. 2011 Jul;29(7):453-8. https://doi.org/10.1089/pho.2010.2917

29. Lopes HB, Ferraz EP, Almeida AL, Florio P, Gimenes R, Rosa AL, et al. Participation of MicroRNA-34a and RANKL on bone repair induced by poly(vinylidene-trifluoroethylene)/barium titanate membrane. J Biomater Sci Polym Ed. 2016 Sep;27(13):1369-79. https://doi.org/10.1080/09205063.2016.1203217

30. Lopes HB, Santos TS, de Oliveira FS, Freitas GP, de Almeida AL, Gimenes R, et al. Poly(vinylidene-trifluoroethylene)/ barium titanate composite for in vivo support of bone formation. J Biomater Appl. 2014 Jul;29(1):104-12. https://doi.org/10.1177/0885328213515735

31. Teixeira LN, Crippa GE, Gimenes R, Zaghete MA, de Oliveira PT, Rosa AL, et al. Response of human alveolar bone-derived cells to a novel poly(vinylidene fluoride-trifluoroethylene)/barium titanate membrane. J Mater Sci Mater Med. 2011 Jan;22(1):151-8. https://doi.org/10.1007/s10856-010-4189-z

32. Teixeira LN, Crippa GE, Trabuco AC, Gimenes R, Zaghete MA, Palioto DB, et al. In vitro biocompatibility of poly(vinylidene fluoride-trifluoroethylene)/barium titanate composite using cultures of human periodontal ligament fibroblasts and keratinocytes. Acta Biomater. 2010 Mar;6(3):979-89. https://doi.org/10.1016/i.actbio.2009.08.024

33. Beloti MM, de Oliveira PT, Gimenes R, Zaghete MA, Bertolini MJ, Rosa AL. In vitro biocompatibility of a novel membrane of the composite poly(vinylidene-trifluoroethylene)/barium titanate. J Biomed Mater Res A. 2006 Nov;79(2):282-8. https://doi.org/10.1002/jbm.a.30801

34. Colnot C. Cell sources for bone tissue engineering: insights from basic science. Tissue Eng Part B Rev. 2011 Dec;17(6):449-57. https://doi.org/10.1089/ten.teb.2011.0243

35. Abuna RP, De Oliveira FS, Santos TS, Guerra TR, Rosa AL, Beloti MM. Participation of TNF- $\alpha$ in inhibitory effects of adipocytes on osteoblast differentiation. J Cell Physiol. 2016 Jan;231(1):204-14. https://doi.org/10.1002/icp.25073

36. Beloti MM, Sicchieri LG, de Oliveira PT, Rosa AL. The influence of osteoblast differentiation stage on bone formation in autogenously implanted cell-based poly(lactide-co-glycolide) and calcium phosphate constructs. Tissue Eng Part A. 2012 May; 18(9-10):999-1005. https://doi.org/10.1089/ten.tea.2011.0405 
37. Dang S, Yu ZM, Zhang CY, Zheng J, Li KL, Wu Y, et al. Autophagy promotes apoptosis of mesenchymal stem cells under inflammatory microenvironment. Stem Cell Res Ther. 2015 Dec;6(1):247. https://doi.org/10.1186/s13287-015-0245-4

38. Al-Hezaimi K, Ramalingam S, Al-Askar M, ArRejaie AS, Nooh N, Jawad F, et al. Real-time-guided bone regeneration around standardized critical size calvarial defects using bone marrow-derived mesenchymal stem cells and collagen membrane with and without using tricalcium phosphate: an in vivo micro-computed tomographic and histologic experiment in rats. Int J Oral Sci. 2016 Mar;8(1):7-15. https://doi.org/10.1038/ijos.2015.34

39. Zigdon-Giladi H, Lewinson D, Bick T, Machtei EE. Mesenchymal stem cells combined with barrier domes enhance vertical bone formation. J Clin Periodontol. 2013 Feb;40(2):196-202. https://doi.org/10.1111/jcpe.12044

40. Zhang H, Shi X, Wang L, Li X, Zheng C, Gao B, et al. Intramembranous ossification and endochondral ossification are impaired differently between glucocorticoid-induced osteoporosis and estrogen deficiency-induced osteoporosis. Sci Rep. 2018 Mar;8(1):3867. https://doi.org/10.1038/s41598-018-22095-1 